SISTEMA
ELETRONIICO
DE REVISTAS
SER I UfPR

\title{
Áreas Protegidas e populações humanas: valor ambiental e manejo sustentável em uma comunidade rural do sul da Bahia, Brasil
}

\section{Protected Areas and populations: environmental value and sustainable management in a rural community in the south of Bahia, Brazil}

\author{
Damile de Jesus FERREIRA ${ }^{1 *}$, Christiana Cabicieri PROFICE ${ }^{1}$ \\ ${ }^{1}$ Universidade Estadual de Santa Cruz (UESC), Ilhéus, BA, Brasil. \\ *E-mail de contato: damileferreira@yahoo.com.br
}

Artigo recebido em 6 de dezembro de 2018, versão final aceita em 15 de outubro de 2019.

RESUMO: O objetivo deste trabalho foi compreender a percepção ambiental dos moradores da comunidade rural do Barrocão (Uruçuca-BA), localizada no entorno do Parque Estadual da Serra do Conduru (PESC), com a finalidade de descrever a relação que os moradores adquiriram com os recursos naturais, a importância que é atribuída aos elementos naturais e suas diferentes formas de manejo. $\mathrm{O}$ estudo é uma pesquisa qualiquantitativa, que emprega a fenomenologia como sua matriz teórico-metodológica. O método de coleta foi o uso de entrevistas semiestruturadas com 13 moradores integrantes da Associação Comunitária Doces Segredos da Floresta. As análises mostraram que os moradores apresentam uma visão sistêmica do meio ambiente, correlacionando a produção da água diretamente com a presença dos fragmentos florestais. Evidenciou-se a responsabilidade socioambiental por parte da comunidade, devido à dependência dos recursos naturais para sobrevivência, além da necessidade do cuidado com o seu lugar. Os moradores apresentaram técnicas de produção que visam à maximização do reaproveitamento, aliadas à discussão da necessidade do cultivo de orgânicos.

Palavras-chave: percepção ambiental; manejo sustentável; agricultura orgânica; Unidades de Conservação.

ABSTRACT: The objective of this work was to understand the environmental perception of the residents of the rural community of Barrocão (Uruçuca-BA), located near the State Park of Serra do Conduru (PESC), in order to describe the relationship that the residents established with the natural resources and the importance it attaches to natural elements and their different forms of management. The study is a qualitative-quantitative research, with phenomenology as its theoretical-methodological matrix. The collection method was the use of semi- 
structured interviews with 13 residents of the communitary association Sweets Forest Secrets. The analyses showed that the residents present a systemic vision of the environment, correlating the water production directly with the presence of the forest fragments. The socio-environmental responsibility of the community was evidenced due to the dependence of natural resources for survival, as well as the need to take care of their place. Residents presented production techniques that aim to maximize reuse allied to the discussion of the need for organic cultivation.

Keywords: environmental perception; sustainable management; organic agriculture; Conservation Units.

\section{Introdução}

A discussão sobre a relação estabelecida entre o ser humano e a natureza se tornou um conteúdo essencial para se entender como se deu a configuração atual da relação do ser humano com o meio, como ele encara o mundo e qual papel lhe é atribuído. Identificar que tipo de relação o ser humano tem com a natureza é reconhecer a natureza de suas práticas perante ela.

Devido ao modelo de desenvolvimento econômico pós-revolução industrial e à ascensão desenfreada do modelo capitalista, calcado na utilização ilimitada dos recursos naturais (Nucci \& Fávero, 2003), a relação entre ser humano e natureza é expressada no âmbito da dominação, manipulação e apropriação dos recursos naturais e de seus ecossistemas.

Este tipo de relação leva a grandes consequências para a manutenção da diversidade biológica e cultural dos ambientes antropizados, constituindo-se em riscos como: o aquecimento global, desertificação, contaminação das águas, desmatamento, perda da biodiversidade, extinção de espécies e diluição da herança cultural. Resultantes da modernização e do desenvolvimento científico-tecnológico, para Beck (2010) estes riscos são provenientes da percepção e da "encenação social" da qual são objeto. A sociedade de risco como a crise ambiental é vista por Leff (2003) como a crise do nosso tempo. Para o autor, a crise se apresenta como a crise do pensamento ocidental: da "determinação metafísica" que, ao pensar o ser como ente, abriu a via da racionalidade científica e instrumental, que produz a modernidade como uma ordem coisificada e fragmentada, como forma de domínio e controle sobre o mundo (Leff, 2003, p. 15).

No intuito de proteção e controle dos recursos naturais, desenvolvimento do turismo e preservação da biodiversidade, foram criadas as primeiras unidades de conservação no Brasil depois do marco legal das áreas protegidas, com o parque Yellowstone em 1872, nos Estados Unidos. Assim, em 1937 foi criado o primeiro Parque Nacional do Brasil (PARNA), o Itatiaia, localizado na Serra da Mantiqueira na divisa entre os estados do Rio de Janeiro e Minas Gerais. Entre 1970 e 1980 o Brasil viveu um cenário de intensa criação de unidades de conservação, as quais se concentraram em grande parte na Amazônia brasileira (Barreto Filho, 2004).

Em 18 de julho de 2000 se deu a criação do principal instrumento legal que regulamenta as Unidades de Conservação (UCs), o Sistema Nacional de Unidades de Conservação da Natureza (SNUC), 
responsável por estabelecer critérios e normas para a criação, implementação e gestão das unidades de conservação federais, distritais, estaduais e municipais. Em concordância com os objetivos e diretrizes do SNUC, categorias foram definidas para melhor direcionamento da gestão e manejo de áreas com características distintas. Elas dividem-se em dois grupos: unidades de proteção integral e unidades de uso sustentável. De acordo com o SNUC (2006), as unidades de proteção integral têm por objetivo básico a preservação da natureza, sendo admitido apenas o uso indireto de seus recursos naturais; já as unidades de uso sustentável objetivam a compatibilização da conservação da natureza com o uso sustentável de parcela de seus recursos.

O Brasil possui 2.376 Unidades de Conservação, distribuídas em todas as categorias dentre a esfera federal, estadual e municipal. Dentre estas, 761 UCs de proteção integral (área de 663.083 km2) e 1.615 UCs de uso sustentável (área de 1.886.247 km2) (MMA, 2019). Em comparação com os dados consolidados de UCs cadastradas em 2014 pelo Ministério do Meio Ambiente, o Brasil até o ano de 2017 criou 243 UCs em um intervalo de três anos, sendo que as unidades de uso sustentável obtiveram um aumento mais significativo do que as unidades de proteção integral.

A configuração das unidades de conservação de proteção integral tem ocasionado inúmeras lutas travadas entre as comunidades locais e as UCs. Devido à separação destas comunidades do processo de conservação da natureza, as UCs acabam se distanciando do conhecimento e do envolvimento das populações que ali vivem. Desta forma, para Diegues (2001), não é possível a eficácia da conservação das UCs com apenas a criação de unidades de conservação, sem que exista a aceitação da comunidade para este fim.
Majoritariamente, a efetivação da política ambiental vigente não favorece o envolvimento das populações que vivem dentro e no entorno das unidades de conservação. Apesar do Sistema Nacional de Unidades de Conservação (SNUC) apresentar em seus objetivos e diretrizes "proteger os recursos naturais necessários à subsistência de populações tradicionais, respeitando e valorizando seu conhecimento e sua cultura e promovendo-as social e economicamente" como também "assegurar a participação efetiva das populações locais na criação, implantação e gestão das unidades de conservação" (Brasil, 2006. Art. $4^{\circ}$ ), o cenário acaba se configurando em expropriações de território da população, lentidão no processo indenizatório e gestões não-participativas.

De acordo com Saraiva (2006), o SNUC ainda não conseguiu apresentar de forma efetiva uma resposta para os problemas que envolvem as populações locais vivendo em áreas de UCs de proteção integral ou próximas a elas além de não mencionar proteção à diversidade cultural e sua importância na conservação da biodiversidade.

A forma pela qual muitas comunidades se relacionam com o meio em que vivem parte do âmbito da sobrevivência e do autoconsumo, em contraste à lógica do acúmulo do capital. Por conseguinte, estas comunidades acabam se conectando com a terra e seus elementos naturais na garantia de proporcionar um ambiente que permita sua reprodução cultural, social, religiosa, ancestral, política e econômica. Viana (1999) classifica essa conexão das populações com a natureza como um envolvimento sustentável, buscando reverter o distanciamento do ser humano em relação à natureza, se envolvendo com os ecossistemas locais e dessa forma criando condições favoráveis para um manejo mais cuidadoso, feitos 
por indivíduos que vivem, convivem, apreciam e conhecem as sutilezas dos ecossistemas naturais.

As diversas formas de percepção e apropriação do meio e de seus recursos resultam em práticas produtivas fundadas na simbolização de seu ambiente, nas suas crenças religiosas e no significado social destes recursos, gerando regras sociais de acesso, práticas de manejo dos ecossistemas e padrões culturais de uso e consumo (Leff, 2009). $\mathrm{O}$ autor coloca que as formas de relação e práticas estabelecidas entre a população humana e a natureza é fruto de uma "cultura ecológica" que visa à reconfiguração das formas de sociabilidade, produção e poder, exigindo a participação da sociedade no processo de reapropriação da natureza, na gestão de seu patrimônio de recursos bioculturais e dos seus bens coletivos.

Neste contexto, esta pesquisa teve como objetivo compreender a percepção ambiental dos moradores da Comunidade Rural do Barrocão em relação ao Parque Estadual da Serra do Conduru BA. Assim, analisou-se a valoração ambiental por parte dos moradores, o significado e importância atribuída aos recursos naturais, a afinidade que eles têm com os recursos naturais locais e suas diferentes formas de manejo.

Vale destacar que o sentido de valor ao qual este estudo remete é o entendimento do valor baseado na utilidade que pode ser atribuída a qualquer objeto pelo qual ele tende a produzir benefício, vantagem, prazer, bem ou felicidade, como afirma Bentham (1979). Assim, valorar algo baseia-se na atribuição de valores aos bens e serviços que possuam alguma utilidade direta ou indiretamente, usufruída por diferentes sujeitos ou grupos.

\section{Metodologia}

\subsection{Conhecendo a área de estudo e suas delimitações}

A comunidade do Barrocão fica localizada a cinco quilômetros do Parque Estadual da Serra do Conduru (PESC), e se encontra em sua zona de amortecimento. A Zona de Amortecimento (ZA) do PESC abrange 25.057,54 hectares de área no entorno, apresenta uma delimitação a um raio de cinco quilômetros ao Oeste e a Norte e dois quilômetros ao Sul e Leste. Além da comunidade integrar a ZA, ela também está inserida dentro da APA da Costa de Itacaré/Serra Grande (Figura 1).

A região compreende áreas remanescentes de Mata Atlântica, estas prioritárias para a atuação de projetos de preservação e conservação devido à extensão dos remanescentes florestais e à grande riqueza de espécies da fauna e flora, considerada atualmente uma das zonas núcleo da Reserva da Biosfera da Mata Atlântica (RBMA). A área do PESC também se encontra no Corredor Central da Mata Atlântica (CCMA), que corresponde a uma rede de unidades de conservação entremeadas por áreas com variados graus de ocupação humana e diferentes formas de uso da terra (Brasil, 2006).

O Barrocão é uma comunidade rural, apesar de seu processo de ocupação territorial ter sido baseado no extrativismo do pau-brasil e outras madeiras nobres, na produção de cana-de-açúcar, café e cacau, na pesca e na pecuária (Bahia, 2005); atualmente tem como sua principal atividade socioeconômica a agricultura, com sua produção voltada tanto para a subsistência quanto para o comércio. Segundo 
consulta aos moradores locais, existem 80 famílias vivendo na comunidade, o que corresponde ao menor número de famílias que têm habitado a região desde o estabelecimento do Parque. Existem duas associações na comunidade: Associação de Moradores do Barrocão, que foi a primeira a ser constituída, em 2011, e a Associação Doces Segredos da Floresta, que foi o foco central desta pesquisa. A Associação Doces Segredos da Floresta é constituída por 13 associados e foi criada burocraticamente em 2014. Desde 2008, a associação participa de programas governamentais como o PAA(Programa de Aquisição de Alimentos) e o PNAE (Programa Nacional de Alimentação Escolar). O engajamento de seus associados e a visibilidade da organização comunitária, incentivaram organizações não-governamentais e instituições socioambientais a investirem na associação com cursos profissionalizantes, visando à capacitação dos moradores para seu desenvolvimento local sustentável.

Algumas destas instituições que contribuíram para o fortalecimento comunitário foram: o Instituto Arapyaú, Instituto Floresta Viva, Associação de Moradores Beira Rio da Represa/Economia

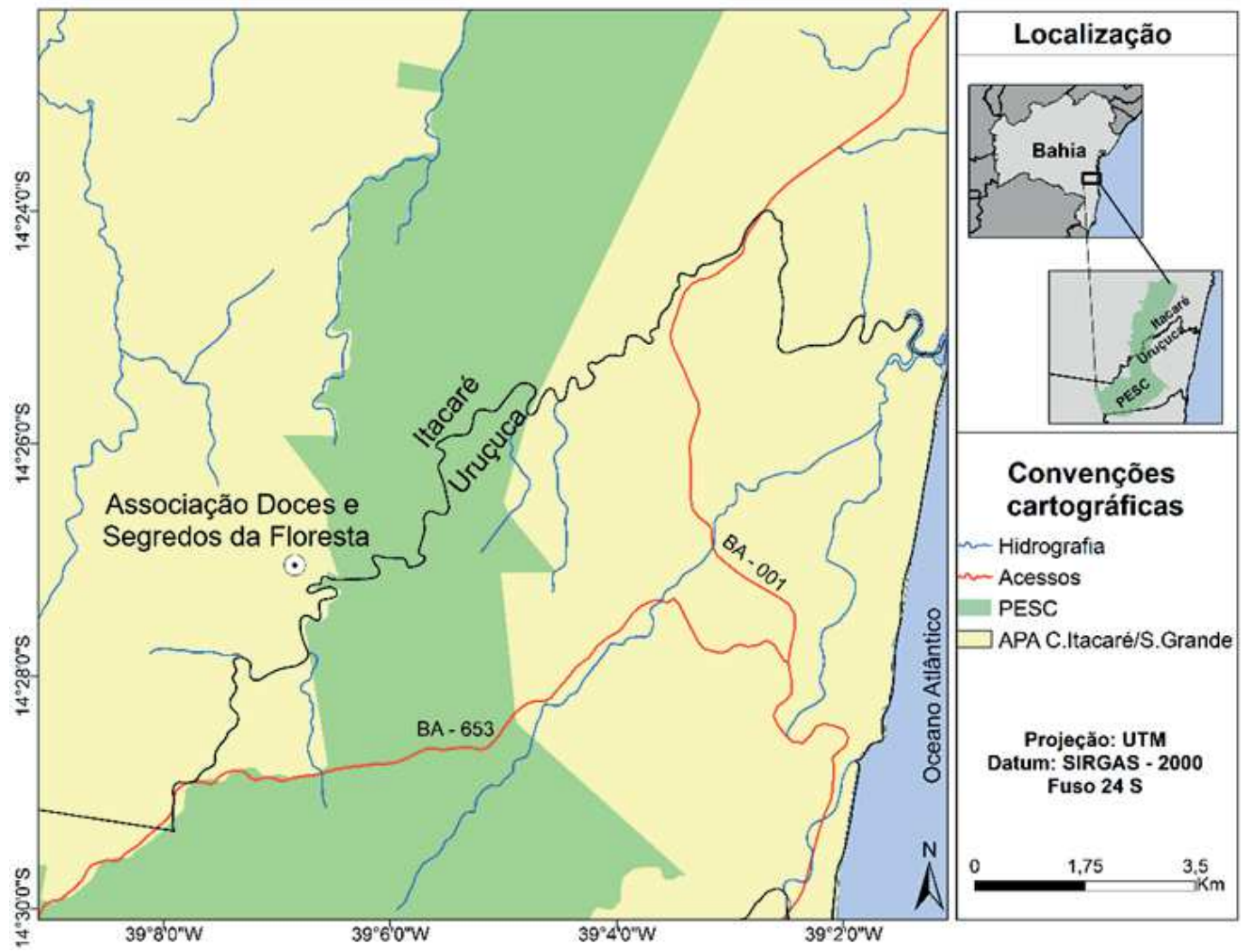

FIGURA 1 - Localização da comunidade do Barrocão e da Associação Doces Segredos da Floresta. AUTOR: Felipe Pimenta, 2017. 
Solidária, Fundo Socioambiental Casa, Tabôa Fortalecimento Comunitário e o Instituto Floresta Viva. As principais metas destas instituições são direcionadas para o desenvolvimento sustentável no Sul da Bahia, conservação de floresta, restauração ecológica, educação e pesquisa, acesso ao conhecimento e estímulo à cooperação.

\subsection{Procedimentos e enfoques metodológicos}

O estudo trata-se de uma pesquisa qualitativa e quantitativa com base na análise de casos concretos em suas peculiaridades locais e temporais, partindo das expressões e atividades das pessoas em seus contextos locais, tendo como interesse o acesso às experiências e interações (Flick, 2009). O trabalho assumiu a perspectiva da investigação qualitativa fenomenológica, já que o eixo norteador da pesquisa foi fundamentado na visão sistêmica e complexa, da matriz teórica, a Fenomenologia. Proceder fenomenologicamente é percorrer o caminho dos sentidos e significados, trabalhando essencialmente com descrições, seja do vivido ou dos significados presentes nas experiências vividas, que são passíveis de compreensão, análise e interpretação.

$\mathrm{Na}$ fenomenologia, a consciência tem como seu primeiro e principal indutor a percepção. Ao acessar o mundo, o sujeito passa a ser um "sujeito perceptivo" em contato direto com o mundo físico. Assim, o primeiro nível de consciência são os atos perceptivos, e o segundo nível se refere aos atos reflexivos. O primeiro nível consiste no momento da relação do sujeito com o mundo mediada pelos sentidos e sensações, resultando nos atos perceptivos. Já o segundo nível remete à reflexão que é feita referente aos atos da percepção. Segundo Bello (2006), a reflexão é uma vivência humana porque corresponde à capacidade que o ser humano tem de se dar conta do que está fazendo, percebendo e registrando aquilo que percebe e se dando conta de que está vivendo o ato da percepção.

Nesse intuito, a interpretação e compreensão da percepção ambiental dos sujeitos da pesquisa foi facilitada utilizando técnicas de pesquisa de campo elaboradas por Whyte (1977) em sua publicação Guidelines for field studies in Environmental Perception. A autora traz em suas diretrizes três abordagens que combinadas orientam no processo investigativo perceptivo: o observar, escutar e interrogar. Foram utilizadas a observação direta e entrevistas semiestruturadas permitindo a compreensão de variáveis referentes às experiências vividas, características individuais e de grupo, identidades, territorialidades, percepções sensoriais, atitudes e comportamentos como realizar tomadas de decisões.

As entrevistas foram direcionadas por um roteiro elaborado com perguntas principais norteadoras, complementadas por questões que surgiram de acordo com a dinâmica do diálogo, possibilitando a emergência de informações de forma mais livre. No total, foram realizadas 13 entrevistas com todos os integrantes da Associação Doces Segredos da Floresta.

Após a concessão de seu consentimento livre e esclarecido juntamente com a aprovação no Comitê de Ética e Pesquisa, as entrevistas com os moradores iniciaram no dia 12 de janeiro de 2017, finalizando-as em 14 de maio de 2017. As entrevistas autorizadas foram coletadas por meio de gravação em câmera e gravador, acompanhada de registros fotográficos. O estudo e análise das entrevistas transcritas foram fundamentadas de acordo com o referencial de Bardin (2009) sobre a análise de conteúdo.

Os dados foram agrupados na categoria valor ambiental, a qual remete-se à resposta cedida à 
proteção do meio ambiente, o significado de importância que é atribuído aos recursos naturais e suas diferentes formas de manejo. Essa categoria evidenciou a percepção ambiental coletiva sobre a importância de conservar os recursos naturais, (re) utilização dos recursos e as atitudes e comportamentos ambientais de cada morador.

Nesse sentido, a análise dos dados foi processada de forma cíclica, existindo um retorno periódico às entrevistas no intuito da busca dos significados precisos e permitindo a realização de inferências.

\section{Resultados e discussão}

\subsection{O perfil dos entrevistados e suas nuances}

Nos dados de identificação de cada entrevistado, foram evidenciadas características como sexo, escolaridade, idade, profissão atual e outras ocupações, lugar de origem e frequência de ida até as cidades próximas.

A característica sexo feminino predominou, com apenas $15 \%$ dos entrevistados do sexo masculino e $85 \%$ do sexo feminino. Este dado mostra a expressiva participação das mulheres tanto na organização da associação, quanto na liderança de atividades e projetos. Durante entrevistas, as mulheres integrantes da associação relataram a importância que ela tem em suas vidas, contribuindo na construção do conhecimento, responsabilidade, solidariedade, organização e autonomia.

A ideia de formar a associação também partiu das mulheres, no intuito de conseguir alternativas que auxiliassem a sua renda familiar. No mundo rural, grande parte das mulheres ocupa a posição de trabalhadoras domésticas, enquanto os homens realizam o trabalho "pesado" na roça, quando não saem para trabalhar na cidade. Mourão (2008) afirma que muitas demandas e sugestões das mulheres são negligenciadas nos processos de desenvolvimento rural, mesmo possuindo um conhecimento da agricultura/roça semelhante ao dos homens.

Em relação à escolaridade, 54\% dos entrevistados possuem o ensino fundamental I incompleto; $23 \%$ o ensino médio completo. Os demais relataram nunca terem frequentado a escola, o que equivale a $8 \%$ dos entrevistados.

A carência de escolas rurais é refletida no número de crianças e adultos que precisam ir para os centros urbanos em busca do ensino. Segundo o Censo Escolar da Educação Básica 2016 (Brasil, 2017), $89,8 \%$ das escolas com ensino médio estão concentradas na zona urbana e $10,2 \%$ na zona rural. Embora 33,9\% das escolas da educação básica estejam localizadas na zona rural, elas detêm apenas $11,4 \%$ das matrículas (5,6 milhões).

A variação da idade dos associados consistiu entre 24 e 60 anos, com uma média de 43 anos. Apenas $38 \%$ dos associados já realizaram outro tipo de trabalho sem estar relacionado com a agricultura. Ao abordar sobre a frequência de ida até a cidade, os relatos mostraram que em média os moradores vão uma ou duas vezes por semana à cidade, passando a maior parte do tempo na comunidade.

Os dados revelaram que $54 \%$ dos entrevistados não são nativos da comunidade e $46 \%$ nasceram no Barrocão. Todos os entrevistados que não são nativos da comunidade vivem e convivem no lugar por um período que varia entre 7 e 38 anos. No entanto, $92 \%$ dos entrevistados não-nativos são mulheres, considerando que geralmente é a mulher que acompanha o homem deixando a família para construir morada junto com seu marido. Esse cená- 
rio se materializa frequentemente no meio rural por questões de organização do trabalho nas unidades de produção familiar e processos sucessórios, que tendem a favorecer os homens na definição do herdeiro do patrimônio fundiário, revelando desigualdades na distribuição das responsabilidades, das decisões e do patrimônio, entre os diferentes membros do grupo (Abramovay, 2001).

\subsection{O Valor Ambiental: representações, ma- nejo e sintropia}

A valoração do meio ambiente, seja através dos serviços ambientais ou de seus recursos naturais, remete inicialmente para a estreita relação entre o sistema econômico e a utilização do ambiente na manutenção da economia. Valorar algo baseia-se na atribuição de valores aos bens e serviços que possuam alguma utilidade direta ou indiretamente, usufruída por diferentes sujeitos ou grupos. No entanto, o sentido de valor em que consistiu o trabalho remete para além da questão utilitária monetariamente, entendendo-se que o valor baseado na utilidade pode ser atribuído a qualquer objeto pelo qual ele tende a produzir benefício, vantagem, prazer, bem ou felicidade, como afirma Bentham (1979).

Ao serem questionados sobre qual o elemento natural que possui maior "valor" para sua vida, os moradores consideraram o elemento água como crucial para sua sobrevivência. A água e as matas foram os únicos elementos citados pelos moradores como mais valorosos para sua vida, sendo que a água foi citada por $77 \%$ dos entrevistados.

Observou-se que água é o elemento essencial para a manutenção e continuação da vida dos moradores. Pelo fato da comunidade estar localizada em uma região com alta densidade de drenagem, devido aos altos índices pluviométricos e a movimentação do relevo que favorece o aparecimento de inúmeras nascentes, córregos, riachos e rios (Bahia, 2005), os moradores acabam não sofrendo com o problema da escassez da água tanto para as atividades domésticas como para a agricultura, já que a atividade agrícola é sua principal ocupação econômica e meio de renda para as famílias. Os relatos abaixo evidenciam a dificuldade da comunidade, se um dia esse recurso acabasse:

É minha filha, nem sei te responder o que a gente faria viu. A gente morre. Sem a água a gente não vive! (M.L.O. S, Barrocão, 12 de janeiro de 2017).

A gente ia morrer... a gente ia morre né? Porque, se não tivesse a água, não teria solo para trabalhar, não teria a terra, como a gente ia sobreviver? (M.S.S, Barrocão, 12 de janeiro de 2017).

Diante da forte dependência com a água, o elemento é visto como fonte de vida, ocupando um lugar sagrado na vida dos moradores. Souza \& Zioni (2003) justificam essa categorização sagrada da água por sua característica transparente e ausência de odores, se associando à ideia de pureza e remetendo à esfera divina. Tuan (2012) aponta que os significados de muitos símbolos são orientados pela cultura, sendo que na psicanálise a água apresenta uma imagem do inconsciente, amorfa mas fertilizadora, uma fonte potencial de força. Dessa forma, a água representa na vida dos agricultores o fator que sustenta e orienta o seu mundo, trazendo consigo a responsabilidade para com este elemento, tanto na questão da disponibilidade como em sua qualidade.

Apesar da mata ser mencionada como elemento de mais valor por apenas $23 \%$ dos entrevistados, ela sempre apareceu nos relatos em associação com a água estabelecendo uma relação de interdependên- 
cia entre ambas. Para os moradores, a preservação das matas é o fator que ocasiona a existência da água na região, considerando o desmatamento um grande risco para o elemento, como mostram os seguintes relatos:

Primeiro eu acho que a mata, porque se desmatar a mata vai acabar com a água, a mata primeiro $e$ depois a água (L, Barrocão, 08 de março de 2017).

Sem a água ninguém vive, porque no caso se você tem uma nascente, ai você corta aquele mato, corta aquelas árvores todas e derruba, aquela nascente vai secar (E, Barrocão, 10 de março de 2017).

A água e a árvores, porque se a gente for desmatar as árvores a água seca, como a gente mesmo sabe, se tiver um rio e a gente for derrubar mata naquele rio, aquele rio vai sumindo (N.J.O, Barrocão, 10 de março de 2017).

Constata-se a visão sistêmica do ambiente por parte dos moradores, conseguindo enxergar as partes que compõem o ecossistema e o que acarreta as suas relações. Mesmo os entrevistados não explicando especificamente como a floresta contribui para a produção da água, a consciência da organização do todo e o seu papel diante desse processo fica explícito em suas falas. As análises mostraram que os agricultores estão conscientes sobre a necessidade e importância de se preservar os fragmentos florestais em decorrência da proteção dos cursos d'água, corroborando o estudo de Dias $\&$ Mota (2015) em comunidades rurais no entorno de uma RPPN. Desse modo, a água e a floresta se completam, a ausência ou desequilíbrio de uma interfere diretamente na existência da outra:

Para mim o mais importante eu acho que é a água, porque através da água eu já posso molhar lá as hortas...não estou dizendo que as árvores não são importantes, é importante porque sem as árvores como é que a gente ia ter água né? Se não...seca tudo e pronto, mas é isso...um depende do outro, por isso que tem que conservar tudo, é solo é tudo (M.R, Barrocão, 10 de março de 2017).

Frente a toda a complexidade do ciclo e processos hidrológicos de uma bacia hidrográfica, o saber ambiental adquirido pelos agricultores sobre a relação entre a água e a floresta consiste na percepção do sistema ecológico por olhares que lapidam e constroem seu conhecimento calcado nas práticas e vivências cotidianas. $\mathrm{O}$ valor significativo que a água e matas têm para os moradores proporciona ações que visam à preservação desses elementos, que ao cuidá-las perpetua sua existência, cultura e seus sistemas de conhecimento.

Questionamentos foram realizados referentes a quem cabe a responsabilidade em proteger e conservar o meio ambiente. O maior número de citações se referiu ao ser humano como principal responsável em cuidar da natureza, com 54\% das citações. Este dado mostra a visão de responsabilidade socioambiental por parte dos moradores, expressando o dever enquanto ator social de proteger o meio ambiente como parte integrante desse meio e dependente dele. Os relatos direcionaram para ações protetivas locais, como não desmatar, queimar e derrubar, não expandindo a questão ambiental e a importância da preservação em nível global. No entanto, Castro (2001) afirma que a relação entre o local e global depende muito do tamanho e fenômeno, sendo que aqueles fenômenos percebidos em escala global diferem muito daqueles percebidos na escala local. Assim, as ações só se concretizam através das práticas sociais nos lugares, já que é a sua diversidade que possibilita a articulação entre as 
determinações globais e as narrativas locais (Rocha \& Monastirsky, 2008).

Os relatos evidenciaram também a necessidade de cuidar do meio ambiente em prol da sobrevivência, dependência e do cuidado com o lugar que é seu lar:

Nós mesmos, eu acho que nós que temos que se responsabilizar para isso, não tem que agredir, a gente vive disso e tem que ter cuidado (E.S, Barrocão, 08 de março de 2017).

Nós mesmo, seres humanos. Eu acho né, que a responsabilidade é de nós mesmo, porque Deus já fez a parte dele né, então temos que fazer a parte da gente. Porque se a gente não proteger, não vai se acabar tudo? Eu acho que responsável é nos mesmo, ser humano (M.S.S, Barrocão, 12 de janeiro de 2017).

Com 31\% de citações o IBAMA, o PESC e a fiscalização ambiental foram vistos como principais responsáveis em proteger a natureza. O IBAMA, por ser a autarquia federal vinculada ao Ministério do Meio Ambiente e responsável pela execução da Política Nacional do Meio Ambiente (PNMA), e o PESC, por se tratar da unidade de conservação local, representando instrumentos existentes para fiscalizar o meio ambiente e impedir ações degradativas. Os moradores reconheceram que a colaboração entre a comunidade e o IBAMA/PESC, é imprescindível para concretizar o processo de preservação:

Eu acho que a partir de nós mesmo, primeiramente nós e depois o órgão que impede e impõe as leis se você agredir a natureza (L, Barrocão, 08 de março de 2017).

A policia ambiental, o gestor, coordenador todos eles, e a gente também tem que proteger, é o governo e a gente também tem que colaborar, a gente vive da natureza (E, Barrocão, 10 de março de 2017).
Com isso, a participação comunitária nos processos decisórios que visam à preservação do meio ambiente por parte dos órgãos ambientais, depende muito do papel indutivo do poder público nos conteúdos educacionais, promovendo o crescimento da consciência ambiental, expandindo a possibilidade da população participar em um nível mais alto no processo decisório, como uma forma de fortalecer sua corresponsabilidade na fiscalização e no controle dos agentes da degradação ambiental (Jacobi, 2003). Desse modo, estimula espaços que possam implementar diversas alternativas para uma gestão participativa, multiplicando informações e motivando os diferentes atores.

Relatos indicaram que a necessidade da presença do IBAMA, e principalmente do parque na região, só existe pelo fato dos moradores não apresentarem a consciência ambiental de preservar a natureza e o ambiente em que vivem. Para os moradores, se a população pensasse coletivamente sobre o cuidado com o meio ambiente e manejasse os recursos de maneira sustentável, a unidade de conservação seria desnecessária na região:

Eu acho que todo mundo né, eu acho que todo mundo devia fazer a parte, se vem um que destrói né, ai vem aquele que não quer que destrua, se eles pensassem todos iguais, eu acho que a natureza seria melhor, não tinha muita devastação [...] Ahhh....se todo mundo fizesse isso não precisava de parque né? Porque o parque vem justamente para proteger daqueles que querem destruir, mas se todo mundo pensasse assim de não destruir, não precisava não (M.R, Barrocão, 08 de março de 2017).

Com a menor frequência de citações, Deus obteve $23 \%$ das citações como responsável em proteger o meio ambiente. Atrelado às ideias cria- 
cionistas, que defendem que Deus criou o universo e todas as coisas terrenas, os entrevistados o colocam em uma posição de ser o responsável por cuidar e zelar dos homens e do mundo, confirmando a sua onibenevolência, onisciência e onipotência. Com essa lógica, muitos moradores se ausentam da responsabilidade de preservar o ambiente já que tudo está nas "mãos” do criador.

Independentemente de quem seja o responsável por preservar o meio ambiente, os relatos mostraram que sua motivação é gerada pelo medo da escassez da água, o ambiente se tornar seco e consequentemente não ter recurso para cultivar a plantação. O desmatamento foi visto como a maior ameaça para o meio ambiente, sendo que apenas um morador mencionou a poluição como uma das causas para proteger o meio.

No que se diz sobre a importância de proteger o meio ambiente, novamente a estreita e sistêmica relação entre a água e a floresta em função da preservação foi o principal conteúdo dos relatos:

Por causa que a seca está aí, se a gente não protege ai que vai ser seca mesmo, a gente protegendo já diminui. Aqui no caso a gente não tem seca, então se a gente não proteger, sair derrubando tudo, acabando com tudo, vai secar mesmo para sempre, vai ter que buscar água fora (E, Barrocão, 08 de março de 2017). Eu acho que por tudo né, sobrevivência, porque se for só acabando, acabando, daqui uns dias fica sem água, os rios mesmo, os nossos córregos não encheram mais depois dessa estiagem que teve de quase 5 meses, 5 a 6 meses de estiagem (L, Barrocão, 08 de março de 2017)".

Para gente não morrer logo né? Tem que proteger as plantas, as árvores, imagine aqui se fosse sem árvores, a gente não ia aguentar, já está com esse tanto de árvore e já está nesse calor absurdo, as árvores, a água, nossos alimentos que tem que cultivar (S.M.S, Barrocão, 12 de janeiro de 2017).
Nota-se a compreensão dos moradores em torno dos impactos ocasionados com o desmatamento na região. Seca, aquecimento global, efeito estufa e períodos longos de estiagem, são impactos negativos que irão surgir com a continuidade das agressões ao meio. O aumento da temperatura é visto como um dos problemas resultantes da derrubada das árvores juntamente com a diminuição da vazão de água dos rios. Para os entrevistados, a floresta possui um papel importantíssimo na determinação da temperatura do ambiente na região, já que o clima é influenciado pela vegetação (principalmente as formações florestais), uma vez que ela é capaz de contribuir para a precipitação em uma região; atuar na descarbonização atmosférica, realizando a mitigação do efeito estufa; e ainda oferecer diferentes microclimas para manutenção da biodiversidade de fauna, flora e microrganismos (Cordeiro; Souza; Mendonza, 2008).

\subsection{Aprendendo com a terra: produção limpa e sustentabilidade}

Dentre os recursos que os moradores retiram da natureza, o destino é exclusivamente para o consumo e para a comercialização na feira livre. $\mathrm{O}$ cultivo das plantações pelos produtores rurais do Barrocão gira em torno da agricultura de subsistência, a qual consiste em um sistema que visa fundamentalmente à sobrevivência do agregado familiar (Correira, 2013) e da agricultura familiar, tendo como objetivo a reprodução da família, podendo apresentar outras formas de produção (Bezerra \& Schlindwein, 2017).

Foram identificadas 25 culturas diferentes produzidas pelos moradores, sendo que 17 delas são culturas de árvores frutíferas e 8 se referem às 
hortaliças. As frutas que são consumidas e vendidas, de acordo com a época de sua produção são as seguintes: banana, abacaxi, açaí, abacate, angicola, cana, cacau, coco, cupuaçu, goiaba, jaca, laranja, limão, manga, maracujá, pupunha e tangerina. Já as hortaliças cultivadas são: agrião, alface, coentro, couve, jiló, repolho, salsinha e tomate.

De acordo com os relatos, a necessidade de comprar alguns tipos de legumes, verduras e frutas na cidade é quase nula, somente em períodos em que a horta não consegue produzir. Os moradores se sentem aliviados e gratificados por não dependerem do comércio externo da cidade para suprir as necessidades alimentícias:

A gente tira só a alimentação, que é banana, é um coco, aipim, coisas mesmo de horta. Verdura que a gente compra mais é uma batatinha, cenoura quando não dá na horta, um repolho, mas é raridade não dar. Quando dá a gente tira tudo dali (M.S.S, Barrocão, 12 de janeiro de 2017).
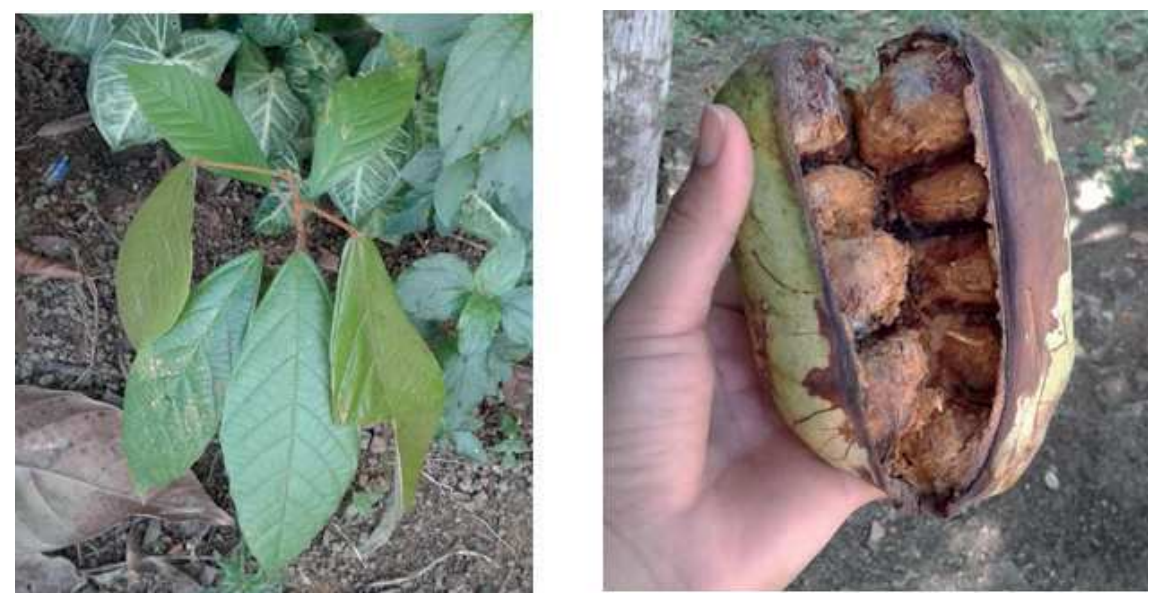

FIGURA 2 - Muda da angicola; Fruto aberto da angicola com suas sementes expostas.

FOTO: Damile Ferreira, 2017. 

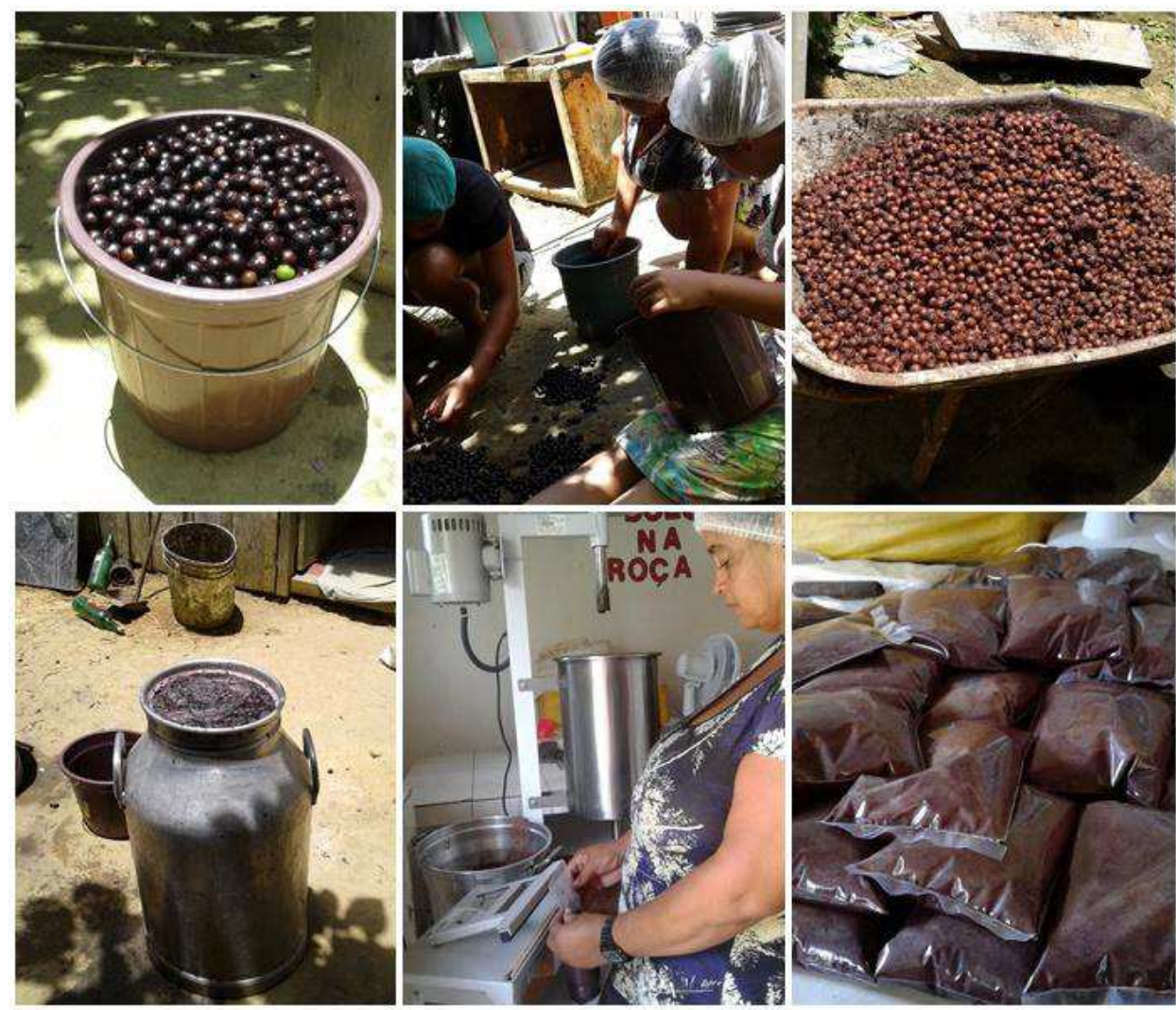

FIGURA 3 - Processo produtivo da polpa do açaí, realizado pelas moradoras da comunidade.

FOTO: Damile Ferreira, 2017.

Como nem todos os moradores possuem plantações de açaí, muitos deles recebem a matéria prima de outro produtor e realizam todo o trabalho braçal, ficando com apenas $20 \%$ do produto final. Com o pagamento realizado em polpas, os moradores vendem o produto nas feiras livres e consegue desta forma obter o lucro devido.

Como uma das principais matérias primas da região do Sul da Bahia, o cacau também se apresenta para os moradores como uma importante fonte de renda, desde o seu cultivo até a comercialização.
A economia cacaueira na comunidade engloba o cultivo da cultura, tanto em seus quintais ou trabalhando como meeiros, a comercialização do fruto e a produção de seus derivados. Para os moradores, o cacau é o recurso potencialmente valorizado, não somente pelo estereótipo que o fruto apresenta na indústria do chocolate, mas pela maximização de seu reaproveitamento. Como relatou uma das moradoras, "[...] do cacau a gente se aproveita quase tudo...quase tudo não, tudo"; assim o cacau é visto como uma fonte de renda garantida, considerando 
que a partir do $2^{\circ}$ ano de plantio os frutos podem ser recolhidos praticamente durante o ano todo.

A maneira mais comum de comercializar o cacau é como fruto e polpa, o mel de cacau é outro derivado bastante vendido, por se tratar do suco in natura das sementes frescas do cacau. O nibs de cacau, conhecido também como amêndoas de cacau, é um produto vendido pelos agricultores, o qual consiste nas sementes torradas e quebradas do cacau. Um dos resíduos do cacau que também é preparado para o comércio, é a sibira ou sibirra. A sibira é uma película que envolve a amêndoa do cacau naturalmente afixada, que são rompidas através de uma fonte de calor e, então, removidas e separadas das sementes limpas. Segundo Kopp e colaboradores (2007), a sibira é uma fonte potencialmente valiosa de nutrientes comestíveis e materiais alimentícios, podendo ser usados para fazer chocolate ou composições de chocolate. Apesar de sua função ser pouco conhecida e nem sempre os moradores conseguirem aproveitar a sibira, ela integra mais uma das opções de renda oriundas do cacau.

A geleia é um derivado que só começou a ser produzido para a comercialização, após a criação da associação. O principal produto da associação atualmente é a geleia produzida a partir do cacau e do cupuaçu, cuja produção os associados almejam aumentar e vender, para além da feira livre.

Pelo fato da comunidade estar inserida na zona de amortecimento do PESC, a derrubada de árvores independentemente de seu fim é proibida e passível de multas pela fiscalização ambiental. No entanto, existe um caso específico de autorização da derrubada: a jaqueira (Artocarpus heterophyllus). A jaqueira é identificada como uma das espécies exóticas invasoras encontradas em UCs federais do Brasil (Chaves et al., 1967; Ferrão, 1993), apresen- tando altas taxas de reprodução, um enorme potencial de dispersão e se configura como uma espécie alelopática. Com isso, a jaqueira é utilizada para a confecção de móveis, contribuindo para o aumento da renda familiar.

O último resíduo do cacau a ser utilizado é a sua casca. Os moradores reutilizam o casqueiro após a quebra do cacau, para a produção de adubo que será utilizado no cultivo da horta. De acordo com Chepote (2003), a casca do fruto do cacaueiro é um subproduto que, normalmente, não é aproveitado nas práticas de adubação do cacaueiro, podendo ser utilizada na alimentação de animais domésticos, na produção de energia (gás metano) e na adubação orgânica sob a forma de composto. Segundo o autor, a compostagem de casqueiros é uma fonte alternativa de fertilizantes, garantindo o fornecimento de macro e micronutrientes para a planta. O relato a seguir mostra a forma de utilização do casqueiro como adubo:

A gente aproveita tudo, a casca do cacau a gente faz adubo, quando está velha eu e meu esposo quebramos todinha e botamos por cima da horta, ela além de ser adubo ela impede que o mato nasça em cima da horta, ela bloqueia muito o nascimento dos matos, dos matos indesejados (L, Barrocão, 08 de março de 2017).

A iniciativa da produção de adubos naturais e o reaproveitamento dos alimentos para a produção de adubos orgânicos surgiu após a criação da associação, onde todos os associados tiveram instruções e cursos de capacitação sobre a agricultura orgânica. O sistema de produção dos produtores rurais do Barrocão que integram a associação Doces Segredos da Floresta passou pelo processo de transição da 
agriculta tradicional para a agricultura ecológica, com o sistema de produção orgânica.

A agricultura orgânica é vista pelos moradores como um sistema de agricultura alternativa, sem a necessidade de agredir a natureza (desmatando e queimando), conciliando dessa forma com as restrições definidas na zona de amortecimento. A prática da agricultura orgânica foi bem recebida pelos associados, pelo fato de ser vista como uma saída diante das proibições da zona de amortecimento, podendo dar continuidade ao estilo de vida baseado na agricultura.

A mudança de comportamento em relação à utilização de fertilizantes químicos e a percepção de risco de todos os indivíduos envolvidos no processo da produção e comercialização são refletidas nos relatos dos moradores, corroborando os resultados encontrados por Silva \& Junior (2010). Valores morais e éticos estão embutidos em suas falas e ações, sendo que o pensamento coletivo é predominante a partir do momento em que os agricultores se importam com a procedência do produto e os riscos que podem oferecer para quem compra. Dessa forma, o objetivo da produção orgânica se distancia da racionalidade econômica que visa apenas ao lucro, buscando o equilíbrio econômico com o ambiental, fornecendo para o mercado produtos mais saudáveis, como pode-se observar em seus relatos:

Muitos põem veneno, só querem tirar, tirar o recurso, mas não se importam se está agredindo, ou matando eles também. Só que tem muita gente de idade aqui que a cabeça é dura, mesmo vocêfalando, explicando que está morrendo, que está dando câncer, mas não entra na cabeça deles. Os jovens só querem tirar a vantagem, só quer tirar renda, ter dinheiro, mas não se importam com o meio ambiente e nem com eles e nem com as pessoas que eles estão vendendo $(\mathrm{L}$,
Barrocão, 08 de março de 2017).

Eu não trabalhava com isso aí (orgânico), eu trabalhava com o plantio de banana da terra, ai era em cima do químico direto. Ai depois da associação que chegou um pessoal, e deu uns cursos e fez esse projeto do orgânico, ai aceitamos (E.A.F, Barrocão, 10 de março de 2017).

Constata-se que o desconhecimento da possibilidade de realizar uma agricultura sustentável, de técnicas para a produção orgânica, da falta de sensibilidade ambiental, da ausência da noção de vulnerabilidade aos impactos expostos e, principalmente, a inexistência de motivação e capacitação voltada para a produção orgânica, configuram-se como fatores intrínsecos para a continuidade na agricultura convencional. Dialogando com essa problemática, Mascarenhas (2004) menciona a escassez de conhecimento em algumas áreas (controle de pragas, adubação, desenhos de SAFs) e a profunda mudança de mentalidade por parte dos agricultores que o processo demanda, como principais dificuldades encontradas pelos produtores.

Ao serem questionados sobre o destino das partes da produção que não são utilizadas, a elaboração de adubo obteve $54 \%$ de citações, alimentação dos animais teve $46 \%$ e dar para os vizinhos possuiu $23 \%$ de citações. Os agricultores relataram que a produção excedente ou aqueles alimentos que não foram vendidos totalmente na feira livre são doados para os seus familiares e vizinhos. O compartilhar se assume como uma característica fundamental no sentido comunitário, sendo reforçado pela noção de cooperação vinda da associação.

Para Kunzler \& Bulgacov (2011), a interdependência e a ação organizacional reduzem a dependência por recursos individuais e ampliam a dependência dos recursos coletivos, conseguindo 
aumentar a produtividade, redução dos custos, facilidade na comercialização, troca de informações e técnicas pelos associados, aumento do convívio social e fortalecimento da cidadania. Dessa maneira, o associativismo rural promove o desenvolvimento e sustentabilidade econômica, ambiental e social das populações locais de pequenos agricultores.

\section{Considerações finais}

As diferentes perspectivas, sentidos e olhares que acabam configurando um mundo tão subjetivo e particular da comunidade se tornaram essenciais para direcionar o mundo material e a realidade na qual estes sujeitos estão inseridos. Assim, compreender a percepção ambiental dos moradores da comunidade rural do Barrocão possibilitou acessar os diferentes significados atribuídos aos recursos naturais e o meio em sua volta, associando a sua importância com os devidos sentidos que lhes são dados.

Foi possível constatar a visão sistêmica dos moradores em relação à água, às matas e as implicações que um elemento causa no outro. A consciência da organização do todo e o conhecimento a respeito da produção da água e sua conservação mostraram que os moradores compreendem os efeitos de suas ações perante o meio. Com isso, foi evidenciado nas formas de manejo dos agricultores o cuidado em preservar os fragmentos florestais em decorrência da proteção das nascentes e dos cursos d'água.

A responsabilidade socioambiental por parte dos moradores em proteger a natureza deixa claro a importância e dependência que eles têm com o meio e seus recursos naturais, além da necessidade do cuidado com o seu lugar.

Por serem pequenos agricultores, o destino final de sua produção consistiu no consumo familiar e na comercialização na feira livre. No entanto, os moradores integrantes da Associação também apresentaram técnicas e formas de produção que visam à maximização do reaproveitamento, dialogando sempre com a importância do cultivo de orgânicos. A Associação no ano de 2018 se encontrava no processo de certificação da produção orgânica para a obtenção do selo orgânico. A certificação da associação estava sendo realizada por meio do Sistema Participativo de Garantia - SPG, sob a certificação de um Organismo Participativo de Avaliação da Qualidade Orgânica - OPAC. No caso da comunidade do Barrocão a entidade certificadora era a Associação Povos da Mata Atlântica do Sul da Bahia, credenciada pelo Ministério da Agricultura, Pecuária e Abastecimento (MAPA), desde agosto de 2016.

O cenário onde se encontram os associados é fruto do trabalho associativo, direcionados para produções sustentáveis, aliado à difusão do conhecimento. Grande parte da capacitação dos moradores se deu por conta de algumas instituições socioambientais que realizaram trabalhos na comunidade.

Nesse sentido, a participação, incentivo, financiamento e a promoção de cursos de capacitação vindos de organizações, poder público e principalmente do PESC foi fundamental e necessária para a garantia da autonomia dos moradores, mudança de comportamento e essencialmente de uma consciência ambiental harmoniosa, ética e sustentável.

\section{Referências}

Abramovay, R. (Org). Impasses sociais da sucessão hereditária na agricultura. Florianópolis: Epagri; Brasília: Nead / Ministério do Desenvolvimento Agrário, 2001. 
Bahia. Plano de Manejo do Parque Estadual da Serra do Conduru, Dezembro, 2005.

Barreto Filho, H. Notas para uma história social das áreas de proteção integral no Brasil. In: Ricardo, F. (Org.). Terras indígenas e unidades de conservação da natureza: o desafio das sobreposições. São Paulo: Instituto Socioambiental, 2004.

Beck, U. Sociedade de Risco: rumo a uma outra modernidade. São Paulo: 34. ed., 2010.

Bello, A. A. Introdução a Fenomenologia. Bauru: Edusc, 2006.

Bentham, J. Uma introdução aos princípios da moral e da legislação. Trad. de Luiz João Baraúna. São Paulo: Abril Cultural, 1979.

Bardin, L. Análise de Conteúdo. Lisboa, Portugal: LDA, 70. ed., 2009.

Brasil. Sistema Nacional de Unidades de Conservação SNUC. Lei $n^{\circ} 9.985$ de 18 de julho de 2000. Decreto $\mathrm{n}^{\circ}$ 4.340 de 22 de agosto de 2002. Brasília, MMA/SBF, 2006.

Brasil. Ministério do Meio Ambiente. O corredor central da mata atlântica: uma nova escala de conservação da biodiversidade / Ministério do Meio Ambiente, Conservação Internacional e Fundação SOS Mata Atlântica. - Brasília, 2006.

Brasil. Ministério da Educação. Censo Escolar da Educação Básica 2016 - Notas Estatísticas, Brasília, 2017.

Bezerra, G. J.; Schlindwein, M. M. Agricultura familiar como geração de renda e desenvolvimento local: uma análise para Dourados, MS, Brasil. Interações, 18(1), 3-15, 2017.

Castro, I. E. O problema da escala. In: Castro, I. E.; Corrêa, R. L.; Gomes, P. C. C. Geografia: conceitos e temas. Rio de Janeiro: Bertrand Brasil, 3. ed., 2001.

Chaves, C. M; Martins, H. F; Carauta, J. P. P; Lanna-Sobrinho, J. P, Vianna, M. C and Silvas. Arboreto Carioca 3. Centro de Conservação da Natureza - Rio de Janeiro - Brasil, 1967.

Chepote, R. E. Efeito do composto da casca do fruto de cacau no crescimento e produção do cacaueiro. Agrotrópica, 15(1), 1- 8, 2003.
Cordeiro, S. A.; Souza, C. C.; Mendonza, Z. M. S. H. Florestas Brasileiras e as mudanças climáticas. Revista Científica Eletrônica de Engenharia Florestal, 11, 2008.

Correira, A. M. A agricultura familiar versus agricultura de subsistência no âmbito da segurança alimentar no espaço dos países da CPLP. Segurança Alimentar e Nutricional na Comunidade dos Países de Língua Portuguesa: Desafios e Perspectivas, Fundação Fio-Cruz e Instituto de Higiene e Medicina Tropical no Rio de Janeiro, 119-133, 2013.

Dias, O. A.; Mota, N. D. Percepção Ambiental em Comunidades Rurais Circundantes a uma Reserva Particular do Patrimônio Natural. Revista Eletrônica de Gestão, Educação e Tecnologia Ambiental, 19(2), 1153-1161, 2015.

Diegues, A. C. O mito moderno da natureza intocada. São Paulo: Hucitec, 3. ed., 2001.

Ferrão, J. E. M. A aventura das plantas e os descobrimentos portugueses. Instituto de Investigação Científica Tropical, Lisboa, 2. ed., 1993.

Flick, U. Desenho da pesquisa qualitativa. Porto Alegre: Artmed, 2009.

Jacobi, P. Educação Ambiental, Cidadania e Sustentabilidade. Cadernos de Pesquisa, 118, 189-205, 2003.

Kopp, G. M.; Pearson, S. M.; Shah, M. S. Processo para moer películas de sementes de cacau, e, produtos de película de semente de cacau, 2007. Disponível em: https://www. escavador.com/patentes/384979/processo-moer-peliculas-semente-cacau-produto-pelicula-semente-cacau?page $=1$. Acesso em: dez. 2018.

Kunzler, M. T.; Bulgacov, S. As estratégias competitivas e colaborativas e os resultados individuais e coletivos no associativismo rural em Quatro Pontes (PR). Revista de Administração Pública - RAP, 45(5), 1363-1393, 2011.

Leff, E. Saber Ambiental: sustentabilidade, racionalidade, complexidade, poder. Petrópolis: Vozes, 3. ed., 2003.

Leff, E. Ecologia, Capital e Cultura: a territorialização da racionalidade ambiental. Petrópolis, RJ: Vozes, 2009.

Mascarenhas, G. C. C. A atual conjuntura socioeconômica e ambiental da região Sul da Bahia e a agricultura sustentável como uma alternativa concreta. In: Uzêda, M. C. (Org.). $O$ 
desafio da agricultura sustentável: alternativas viáveis para o Sul da Bahia - Ilhéus, Ba: Editus, 13 - 32, 2004.

MMA - Ministério do Meio Ambiente. Cadastro Nacional de Unidades de Conservação, 2019. Disponível em: <www. mma.gov.br/images/arquivo/80229/CNUC_JUL19\%20 -\%20B_Cat.pdf>. Acesso em: dez. 2019.

Mourão, P. L. Diagnóstico das potencialidades das produções realizadas pelas mulheres rurais (relatório no. 4). Consultoria prestada junto ao Ministério do Desenvolvimento Agrário. Projeto de Cooperação Técnica MDA/FAO - UTF/ BRA/057/BRA. Brasília, 2008.

Nucci, J. C.; Fávero, O. A. Desenvolvimento Sustentável e Conservação da Natureza em Unidades de Conservação: o caso da Floresta Nacional de Ipanema (Iperó/SP). R. $R A$ ' $E$ GA, 7, 63-77, 2003.

Rocha, A. R. P.; Monastirsky, L. B. Turismo e patrimônio cultural: a dialética da globalização. V Seminário de Pesquisa em Turismo do MERCOSUL - Turismo: Inovações da Pesquisa na América Latina; Caxias do Sul, 2008.
Saraiva, R. C. F. Tradição e Sustentabilidade: um estudo dos saberes tradicionais do Cerrado na Chapada dos Veadeiros, Vila São José - GO. Brasília, Tese (Doutorado em Desenvolvimento Sustentável) - UnB, 2006.

Silva, A. J.; Junior, M. F. S. Representações Sociais e agricultura familiar: indícios de práticas agrícolas sustentáveis no Vale do Bananal - Salinas, Minas Gerais. Sociedade \& Natureza, 22(3), 525-538, 2010.

Souza, D. V.; Zioni, F. Novas perspectivas de análise em investigações sobre meio ambiente: a teoria das representações sociais e a técnica qualitativa da triangulação de dados. Saúde e Sociedade, 12(2), 76-85, 2003.

Tuan, Y-F. Topofilia: um estudo da percepção, atitudes e valores do meio ambiente. Londrina: Eduel, 2012.

Viana, V. M. Envolvimento Sustentável e Conservação das Florestas Brasileiras. Revista Ambiente \& Sociedade, 5, 1999.

Whyte, A. Guidelines for field studies in Environmental Perception. Technical Notes 5. Paris: UNESCO, 1977. 